\title{
Morphological changes of alveolar bone due to orthodontic movement of maxillary and mandibulary incisors
}

Pinandi Sri Pudyani, Darmawan Sutantyo, and Sri Suparwitri

Department of Orthodontic

Faculty of Dentistry Gadjah Mada University

Yogyakarta - Indonesia

\begin{abstract}
Ideally in orthodontic tooth movement, alveolar bone will follow its movement, therefore, the ratio between bone remodeling and tooth movement is 1:1. The problem whether the ratio is valid for all kinds of tooth movement such as: tipping, torquing, or bodily, or it could be applied in tooth movement of all directions such as facially, lingually or sagitally. Various studies also showed many different ideas. Some studies state that root dehiscence and fenestration are frequently found in final orthodontic treatment and some other state that bone remodeling can compensate tooth movement. The purpose of this study was to know the changes of alveolar bone morphology caused by anterior tooth movement. The conclusion is remodeling compensation is not matched with the extension of tooth movement, thus there are many cases of root dehiscence and fenestration after orthodontic treatment.
\end{abstract}

Key words: alveolar bone, tooth remodeling, orthodontic tooth movement

Correspondence: Pinandi Sri Pudyani, c/o: Bagian Ortodonsia, Fakultas Kedokteran Gigi Universitas Gadjah Mada. Jln. Denta, Sekip Utara Yogyakarta 55281, Indonesia. E-mail: orto_fkgugm@yahoo.com

\section{INTRODUCTION}

During orthodontic treatment, mechanical force applied in tooth will cause alveolar bone reaction. ${ }^{1}$ The mechanic force which applied will move the tooth orthodontically and being continued to the entire tissue resulting the occurrence of remodeling process. ${ }^{2}$ Orthodontic force will result in the alteration of regulating alveolar bone function as well as its cell. ${ }^{3}$ The alteration is including bone formation on tension side and bone resorption on pressure side thus the tooth will move to the new position. The process of bone formation involving osteoclast. ${ }^{4-9}$ Mechanism correlates with cell activation due to mechanical force is still unknown up to now, however, the evidence has shown that electric current appears on compressed tissue. ${ }^{10,11}$

Excessive force will cause the damage of periodontal tissue on pressure region, the adjacent bone will be necrotic followed by undermining resorption. ${ }^{12}$ Similarly, excessive force will cause injury by principle fibers rupture in periodontal ligament, and a part of alveolar bone will be necrotic $^{13-15}$ due to vessel injury. The pressure which is exceeded than the blood pressure will make capillary blood vessel in periodontal ligament collapse, which can inhibit the blood supply. On the contrary, if maximal pressure applied is lower than the blood pressure, the capillary blood vessel will not collapse, therefore, optimal force to move the tooth should not be higher than capillary blood vessel. ${ }^{16}$

Direct alteration occurs in reconstructive step of alveolaris processus, but, if the tooth is continuously moved tipping toward the palate, alteration will be in cortical palate of alveolar processus, ${ }^{1}$ therefore, the current study has discussed on the limitation of tooth movement which could be improved by alveolar bone remodeling. ${ }^{13-15}$ Excessive orthodontic force which is frequently applied in orthodontic practice will not move the tooth any furher, but it will cause excessive load on periodontal tissue and as a result it will inhibit tooth movement. ${ }^{7-8}$ Some studies still showed various ideas on the changes of alveolar bone due to anterior tooth movement. It is caused by alveolar tooth remodeling as a response to various tooth movement in every person. If tooth movement area is limited, excessive orthodontic force will cause cortical bone resorption and root exposure will also occur because the tooth loses the supporting tissue i.e. alveolar bone. Various opinions appear such as whether the capacity of bone alveolar remodeling can compensate the loss bone. ${ }^{15}$ Some researchers suggested that root dehiscence will occur if the tooth is moved facially. ${ }^{17}$ Others said that incisors retraction and root torque will not change anterior palate width on the root margin. Alveolar bone remodeling can occur on half of the root and alveolar margin, if the tooth gets closed to or surpasses lingual cortex. The purpose of the study is to know various morphological changes of alveolar bone due to orthodontic movement of maxillary and mandibular incisors.

\section{Anatomical form of alveolar bone in malocclusion}

Handelman ${ }^{18}$ observed the comparison of partial alveolar bone on various cases of malocclusion. The width of alveolar bone of linguo posterior part toward upper incisor apex (UP), labioanterior of alveolar bone to upper incisor apex (UA), linguo posterior of alveolar bone (LP), 


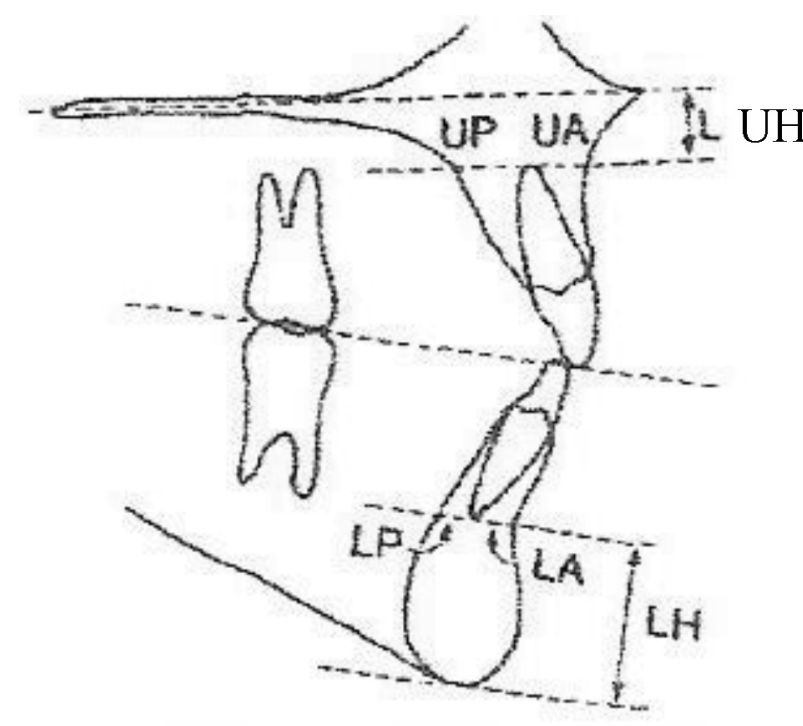

Figure 1. UP, UA, LP, LA, UH, LH.

labioanterior to lower incisor apex (LA), superior part to upper incisor apex (UH), and inferior part to lower incisor apex (LH) were observed. The result showed UH and LH in Angle class III malocclusion was bigger than class I. LP in class III was narrower than class I and II In group of divergent mandible, UP was bigger in low SN (SellaNation)-MP (Mandibular Plane) group while in SN-MP average or high groups, found wider LP. Edwards ${ }^{1}$ did not find any difference in alveolar bone width in divergent mandible case.

\section{The effect of incisor facially tipping movement on alveolar bone morphology}

The changes of alveolar bone and cementum on incisor facially tipping movement have been observed. In this study, extrusion has also occurred. Extensive apposition found in mesial, distal and lingual region on extrusive tooth. On lingual and interproximal surface, the distance between cementum enamel junction and alveolar crest is $1 \mathrm{~mm}$ longer than controlled group. Alveolar dehiscence is found on the facial surface of tooth which is facially moved and extruded. ${ }^{19}$ In the study done on the monkey, $1.7 \mathrm{~mm}$ bone loss was found in the tooth which was moved facially, in controlled group $1.3 \mathrm{~mm}$ bone loss was found, but statistically it is not significant. ${ }^{17}$

\section{The effect of lingual tooth movement on alveolar bone mor- phology}

A study has been done on the changes of alveolar bone thickness in retraction of anterior tooth in bimaxillary protrusion with 4 premolar teeth extracted. CT scan and cephalogram examinations were done before treatment and 3 months after incisive tooth retraction. The first step, lingual tipping movement was done in maxillary and mandibulary incisors. The first slice on CT scan was done on labial and lingual region of alveolar bone. The result was: more alveolar bone loss occurred in the middle tooth margin than in apical region. The bone thickness on lingual part of maxillary lateral incisors decreases more than lingual part of maxillary central incisors. This can be due to the force given to the forth incisive is similarly spreading among the teeth. In maxilla, periodontal ligament area of central incisors is bigger than lateral incisors, therefore, the pressure was concentrated on cortical alveolar plate in lateral incisor region so it caused more thickness decrease in lingual cortical plate. In anterior mandible region, each of incisor has the same number of periodontal ligament and would get the same pressure. This case would cause different change of bone thickness in maxilla. In mandible, the quantity of alveolar bone loss is the same with the forth incisors. ${ }^{15}$

The change of buccal alveolar bone morphology in mandibulary incisors lingual retraction in protrusion case has been observed. The result of the study suggests the increase of buccal alveolar bone height in $58.8 \%$ cases, while in the rest, $41.2 \%$ cases was decreasing. ${ }^{20}$

\section{The effect of extrusive and intrusive tooth movement in alveolar bone}

Extrusive tooth movement will cause stretching of supracrestal and principle fibers with bone formation in apical alveolar crest of extrusive tooth. Principle fibers will re arrange the position and will return faster to normal condition during retention period, but supracrestal fibers will be constantly stretched in longer time. ${ }^{19}$ Intrusive tooth is still a controversial problem in some literatures, because the occurrence of iatrogenic damage in tooth supporting tissue was reported. ${ }^{21}$ Tooth intrusion causes various changes of alveolar tissue. Cementum resorption in tooth apex and reorientation of periodontal fibers direction based on intrusive tooth movement are found. ${ }^{22}$ Intrusive tooth contributes pressure on supra alveolar fibers and the pressure will result in alveolar crest remodeling. ${ }^{23}$ Other study reported the occurrence of resorption in alveolar laminal bone and cementum on experimented animal (monkey) and there was compression in apical periodontal ligament if mandibulary incisor was intruded. ${ }^{24}$ The stable periodontal tissue was found in intrusive tooth done in extrusive tooth with infra bony disorder. ${ }^{25}$

\section{The ratio of cortical bone remodeling and tooth movement during maxillary incisors retraction}

The well known axiom in moving the tooth is that the bone will follow the trace of the moving tooth. If tooth movement occur due to orthodontic force, the bone around the tooth socket will remodel in the same width with tooth movement, so, the ratio between remodeling bone and tooth movement is $1: 1$. Vardimon $^{14}$ compared the ratio of maxillary incisors retraction with tipping and torque movement. It was found that either tipping or torque movement would not produce ratio 1:1. In tipping movement the ratio was $1: 2$, meant that if the apex of central incisors moves $3 \mathrm{~mm}$ posteriorly, so A point would be retracted $1.5 \mathrm{~mm}$. The ratio for torque movement was 
1:2.35; meaning if the apex of central incisors moved $5 \mathrm{~mm}$ posteriorly, A point would be retracted closely $2 \mathrm{~mm}$. It is said that mechanical component in retraction and tipping movement would decrease the risk of central incisors apex moved closely to labial cortical plate. It is recommended to use the ratio 1:2 to decide the prognosis of point A-P movement or $\mathrm{P}-\mathrm{A}$ in maxillary central incisors movement.

\section{DISCUSSION}

The result of recent study has shown that limitation of tooth movement could be compensated perfectly by remodeling process. ${ }^{13-15}$ If extensive palatal tooth movement was done, the tooth root would be contacted with palatal cortex of alveolar bone. ${ }^{1}$ Cortex would bend and limited movement would occur. If contact occurred, further movement would cause perforate of cortical plate followed by bone loss, root resorption and relapse. Adaptation phenomenon of bone form on pressure showed that bone at any time can change it self by pressure, increasing or decreasing the mass to compensate the force. ${ }^{26}$

In the condition that cortical plate has been penetrated by root, the surface of buccal root will not be covered by the bone. Although osteogenesis process may occur for four months in retention period, it is not sufficient to cover the whole root surface. It is said that repair of root penetration region will only occur if the tooth comes back to it is original position (relapse). ${ }^{27}$

In the area of limited movement, excessive force will cause the tooth touching the cortical plate of alveolar bone, so, cortical bone resorption and root penetration will appear. Tooth movement in limited area can contribute alveolar bone loss and it is still debatable whether the capacity of alveolar bone remodeling can compensate in every case of alveolar bone loss. Many experts have an opinion that extensive incisors movement should be avoided to prevent cortex distraction of lingual alveolar bone resulting in tooth supporting tissue loss. ${ }^{15}$

It has been observed the alteration of alveolar bone resulting from incisors retraction in class II malocclusion with bimaxillary protrusion. The result of the study stated that even though retraction and torque of tooth root have been done for long, the width of palatal alveolar bone around the tooth will not change. Alveolar bone remodeling can occur on half of the root and alveolar margin, Apical area is the border of orthodontic tooth movement. ${ }^{1}$ The opposite study stated that decrease of alveolar bone thickness more frequently occurs in coronal tooth region and the middle of tooth root than in apical. ${ }^{15}$

Some experts found morphological changes of alveolar bone in incisors movement. In narrow simphisis mandible case, sagittal tooth movement and tooth derotation is critical condition and it can cause labial and lingual cortical plate loss and tooth decrease alveolar bone height. ${ }^{28}$ After oval root tooth derotation, the width of sagittal bone is adequate to support lingual and labial cortical plate. During derotation of root with oval form, two sides affected by pressure and tension. In distally rotation case, both sides are mesiolingual and distolabial root side, so, more root reception is found on that side.

To move incisors, optimal stability will be reached if the tooth located in medula region of alveolar bone and in good balance with labial and lingual muscles. Positioning incisors perpendicular towards basal bone will increase the support around the root of incisors and will produce good periodontal tissue condition. ${ }^{15}$

Basic axioma states that bone will follow the trace of tooth movement, therefore it is assumed that the ratio between bone remodeling and tooth movement is $1: 1$. The problem is whether the ratio is the same for anteroposterior, vertical and transversal. On vertical dimension, dehiscence and fenestration of buccal cortical plate in rapid maxillary expansion has been reported. It is assumed that root movement in buccal dental segment will inhibit lateral remodeling bone. In this case, the question is whether the ratio 1:1 can be applied in slow expansion treatment. ${ }^{14}$

In sagittal dimension, different reaction is found in anterior and posterior segment. In posterior segment, ratio 1:1 still can be applied as long as tooth movement is limited between two cortical plates because it will intermitently influence the cancelous bone. ${ }^{14}$ In anterior segment, palatal or labial cortical plate is involving in the whole anteroposterior movement either in maxillary or mandibulary anterior tooth. Ratio 1:1 will not occur in anterior segment. Protraction of maxillary incisors can contribute dehiscence of labial cortical plate ${ }^{29}$ which is reversible if the tooth returns to its initial position (relapse). ${ }^{14}$

Ratio 1:1 between the number of remodeling bone and tooth movement was not found after 3 months retention period after incisors retraction. At the end of treatment, dehiscence and fenestration were found in coronary region and middle of tooth root. The width of alveolar bone in apical region decreases but the level of alteration was small, therefore bone dehiscence did not occur. Based on the result, it is considered that the width of marginal alveolar bone and middle tooth root is similarly important with apical alveolar bone. It is concluded that remodeling bone is not always in the same quantity with the number of tooth movement. ${ }^{15}$

Increasing the height of buccal alveolar bone is reported after retraction of mandibulary central incisors. Of the 17 cases, $58.8 \%$ showed increasing the bone height in buccal region, while the rest would get decreasing height. Increasing bone height in that region is thought not only due to angulations changes between mandibular plane and mandibulary central incisor axis but due to tooth intrution. $^{20}$

Alveolar bone resorption might be caused by too far tooth movement, narrow alveolar bone and symphisis and oval form tooth root. Based on the studies done by Vardimon, ${ }^{14}$ Sarikaya ${ }^{15}$ and Wehrbein ${ }^{28}$ it can be conclude 
that compensation of remodeling bone is not matched with the number of tooth movement so there are many dehiscence and fenestration found at the end of orthodontic treatment.

To overcome this problem, therefore, prior to orthodontic treatment, evaluation of the bone structure and anterior tooth is necessarily done, thus stable position can be reached after treatment and adverse effect on tooth supporting tissue will not occur. In incisors movement, optimal stability will be reached if the tooth is in medulary region of alveolar bone and in good balance with labial and lingual muscles. Perpendicularly positioning incisive towards basal bone will increase the support around the root of incisors and will produce good periodontal tissue condition.

\section{REFERENCES}

1. Edwards JG. A study of anterior portion of the palate as it relates to orthodontic therapy. Am J Orthod 1976; 69(3):249-73.

2. Yun Cho. A histologic study of the alveolar bone remodeling on the periosteal side incident to experimental tooth movement. Dent in Japan; 33:79-82

3. Sandy J, Farndale RW, Meikle MC. Recent advances in understanding mechanically induced bone remodeling and their relevance to orthodontic theory and practice. Am J Orthod Dentofac Orthop 1993; 103(3):212-21.

4. Noxon JS, King GJ, Gu G, Meikle MC. Osteoclast clearance from periodontal tissues during orthodontic tooth movement. Am J Ortod Dentofac Orthop 2001; 120(5):466-76.

5. Rody W, King GJ, Gu G, Huang G. Osteoclast recruitment to sites of compression in orthodontic tooth movement. Am J Orthop Dentofac Orthop 2001; 120(5):477-89.

6. Kohno S, Kaku M, Tsutsui K, Motokawa M, Ohtani J, Tenjo K, et al. Expression of vascular endothelial growth factor and effects on bone remodeling during experimental tooth movement. J Dent Res 2003; 177:177-82.

7. Ren Y, Martha J, Hof V, Kuijpers Jagtman AM. Optimum force magnitude for orthodontic tooth movement: A mathematic model. Am J Orthod Dentofac Orthop 2004; 125(1):71-7.

8. Ren Y, Maltha JC, Kuijpers Jagtman AM. Optimum force magnitude for orthodontic movement: A systematic literature review. Angle Orthod 2003; 73:86-92.

9. Cronau M, Ihlow D, Meesenburg K, Fanghanel J, Dathe H, Nageri H. Biomechanical features of the periodontium: An an experimental pilot study in vivo. Am J Orthod Dentofac Orthop 2006; 129:599.

10. Davidovitch Z. Bone metabolism associated with tooth eruption and orthodontic tooth movement. J Periodontol 1975; 48:22-9.

11. Davidovitch Z, Vinkelson MD, Stegman S, Sfanfeld JL, Montgomeri PC, Korostoff. Elective currents, bone remodeling and orthodontic tooth movement part I: the effect of electric currents on periodontal cyclic nucleotides. Am J Orthod 1980; 77:14-32.

12. Melsen B. Biological reaction of alveolar bone to orthodontic tooth movement. Angle Orthod 1999; 69(2):151-58

13. Meikle MC. The dentomaxillary complex and overjet correction in class II, division 1 malocclusion: objectives of skeletal and alveolar remodeling. Am J Orthod 1980; 71(2):185-97.

14. Vardimon AD, Oren E, Bassat, YB. Cortical bone remodeling/ tooth movement ratio during maxillary incisor retraction with tip versus torque movements. Am J Ortod Dentofac Orthop 1998; 114(5):520-9.

15. Sarikaya S, Haydar B, Ciger S, Ariyurek MA. Changes in alveolar bone thickness due to retraction of anterior teeth. Am J Orthod Dentofac Orthop 2002; 122(1):15-26.

16. Choy K, Pae EK, Park YC, Kim KH, Burstone J. Effect of root and bone morphology on the stress distribution in dental periodontal ligament. Am J Orthod Dentofac Orthop 2000; 117(1):98-105.

17. Wingard CE, Bowers GM. The effect on facial bone from facial tipping of incisors on monkeys. J Periodontol 1976; 47(8):480-544.

18. Handelman CS. The anterior alveolus: its importance in limiting orthodontic treatment and its influence on the occurrence of iatrogenic squeal. Angle Orthod 1996; 66(2):95-110.

19. Batenhorst KF, Bowers GM, Williams JE. Tissue changes resulting from facial tipping and extrusion of incisors in monkeys. J Periodontol 1974; 45(9):660-68.

20. Bimstein E, Crevoisier RA, King DL. Changes in the morphology of the buccal alveolar bone of protruded mandible permanent incisors secondary to orthodontic alignment. Am J Orthod Dentofac Orthop 1990; 97(5):427-31.

21. Melsen B. Tissue reaction following application of extrusive and intrusive forces to teeth in adult monkeys. Am J Orthod Dentofac Orthop 1986; 89(6):469-75.

22. Melsen B, Agerbaek N, Markenstam G. Intrusion of incisors in adult patients with marginal bone loss. Am J Orthod Dentofac Orthop 1989; 96(3):232-41.

23. Kanzeki R, Daimaruya T, Takahashi I, Mitani H, Sugawara J. Remodeling of alveolar bone crest after molar intrusion with skeletal anchorage system in dogs. Am J Orthod Dentofac Orthop 2007; 131(3):343-51.

24. Murakami T, Yokota S, Takahama Y. Periodontal changes after experimentally induced intrusion of the upper incisors in Macaca fustata monkeys. Am J Orthod Dentofac Orthop 1989; 95(2):115-26.

25. Cardaropoli D, Re S, Corrente G. Intrusion of migrated incisors with infrabony defects in adult periodontal patients. Am J Orthod Dentofac Orthop 2001; 120(6):671-5.

26. Kukihara S, Enlow DH. A histochemicaland electron microscopic study of an adhesive type of collagen attachment on resorptive surface of alveolar bone. Am J Orthod 1980; 77:532, 546.

27. Wainwright WM. Faciolingual tooth movement: Its influence on the root and cortical plate. Am J Orthod 1973; 64:278-302.

28. Wehrbein H, Privatdozent, Bauer W, Diedrich P. Mandible incisors, alveolar bone, and symphysis after orthodontic treatment. A retrospective study. Am J Orthod Dentofac Orthop 1996; 110(3):239-46.

29. Engelking G, Zachrisson BU. Effect of repositioning on the monkey periodontium after expansion through the cortical plate. Am J Orthod $1982 ; 82: 23-32$. 